\title{
Isuri rahvamuusikast
}

\author{
Igor Tõnurist
}

Oleme taas Ingerimaal, täpsemalt Lääne-Ingeris, mis asetseb Narva ja Neeva jõe vahelisel alal ning kuulame ühe Ingeri põlisrahva - isurite - rahvapillimuusikat. Tuletan meelde, et 1989. aasta rahvaloenduse järgi oli isureid vaid veidi üle 800 inimese. 60 aastat varem loendati neid üle 26000 . Isurite venestumine algas juba ammu, sest venelastega ühendas neid ja ka nende naabreid vadjalasi ühine usutunnistus - vene õigeusk. Surmahoobi andsid 1937. aasta stalinlikud repressioonid, seejärel II MS sündmused, mil isureid, vadjalasi, ka ingerisoomlasi küüditati esialgu Soome, sealt tagasipöördumisel aga nn. nõukogude kodumaa avarustele. Vaatamata kõigele pole iidne folklooritraditsioon siiski katkenud ning isuritelt ja vadjalastelt on kuni viimase ajani üles kirjutatud regivärsilisi rahvalaule. Külakarjused puhuvad siin-seal oma pasunaid, isegi kandlehelid pole vaibunud.

* 1. Laulu esitab Fenja Filippova, kes 1975. a. elas muide Tartus.

Huvitava elukäiguga isuri mees Fjodor Safronov sündis 1886. aastal Ingeris, Soikkola poolsaarel Viistina külas. Saatus viis ta Soome, kuhu ta I MS järel alatiseks elama jäi. Ta suri Helsingis 1962. a. ja seal kutsuti teda juba Teppo Repo. Ta tegi mitmesuguseid töid, oli isegi politseiks Helsingis, parandas õmblusmasinaid ja muudki, kuid tuntuks sai ta Soomes kui ingeri rahvapillide tegija ja mängija. Teppo Repo lugusid on avaldatud mitmel heliplaadil. Viimati avaldati 45 Teppo Repo pillilugu Soomes CD-plaadil. Teppo Repo lugu * 2. Ema itku viis esitatakse sarvel. Itkulaulu instrumentaalne imiteerimine kuulus nii isuri kui ka vene, leedu ja meie setudegi pillimuusikatraditsiooni.

Omapärast pilli nimetas Teppo Repo ise jalutuskepiks - kävelukeppi. See oli pikk puust vilepill, mis oli pealt kasetohuga mähitud. Mänguauke sellel polnud üldse ning helide kõrgust sai muuta kas reguleerides suuga puhumistugevust või sulgedes-avades sõrmega vilepilli alumist ava. See sarnaneb Läänemaal kunagi tuntud pikkvilele.

Isuri pulmalauluviisi võidi mängida kahel "jalutuskepil" korraga. Niimoodi pole küll Ingeris kunagi mängitud, kuid Teppo Repo oli tõeline rahvapillimees, kes kõik huvitava kohe üle võttis. Korra tutvunud ta soome rahvamuusikateadlase Armas Otto Väisase juures mordva paarisroopilliga ja suur olnud Väisase imestus, kui Teppo Repo mänginud talle mõni aeg hiljem kahel isuri vilepillil korraga nii oskuslikult nagu teinuks ta seda varemgi. Teppo Repo käes on paarisvilepill kurioosum, kuid paarisvilepilli, ehk siis valipilli, on mängitud meil Setumaal, Lääne-Venes ja Valgeveneski.

Kasetoht ehk siis tohupill on vist kõigi Põhja-Euroopa rahvaste ühine muusikariist.

Ingeris oli tuntud veel torupill, mida seal nimetati rakkopill, ehk siis põispill, sest torupilli tuulekott tehti seapõiest. 1967. a. õnnestus mul veel fikseerida mälestusi vadja-isuri rakkopillist. Kirjelduste põhjal tegin tookord rekonstruktsiooni ning selle põhjal identifitseeriti hiljem ka vadja torupilli jäänused Soome Rahvusmuuseumis, mida säilitati niiöelda määramata otstarbega etnograafiliste esemete hulgas. Ingeri torupill osutus oma ehituselt väga arhailiseks, sellist polegi Läänemere idakallastel varem leitud. Vadja torupilli mainitakse esmakordselt juba XVIII saj. lõpus. Huvitav on 
Fjodor Tumanski märkus, et tshuudidel, st. vadjalastel, pole mingisuguseid muusikariistu, ainult väga harva, ja sedagi kõrvaliste pidustuste puhul, kutsuvad nad eestlase torupilliga. Pulmas aga ei mängita eales pilli, ainult lauldakse ja tantsitakse laulu saatel. Kirjeldades isurite pulmakombeid mainib ta jällegi, et tantsitakse laulu saatel ilma torupillita. Mõnedes üsna Eesti lähedal asuvates vadja külades oli siiski XIX saj. teisel poolel pruuti tantsitatud torupilli saatel. Pruudi rituaalse tantsitamise komme oli ilmselt eestlastelt üle võetud. Kannelt nimetavad vadjalased kannõl ja isurid kannel. Teppo Repo esituses kõlab *3. Peipposenpolka, mis tegelikult on sajandivahetuse vene moelugu. See oli Eestiski tuntud. Meie rahvatantsijad tunnevad teda vististi Kodavere tantsu Siisikuna. Siisik ongi 'tzhisik' ehk metsvint.

Ka kandlelugu * 4. Sääse kargamine on sajandivahetusest pärit vene viis.

Ingeris mängiti kannelt nn. katmistehnikas, kattes vasaku käega osa keeli ning tõmmates parema käega lahtised keeled helisema. 6-keelsetel kanneldel mängiti vanasti meil Setumaalgi nii, et pandi vasaku käe sõrmed keelte vahele ning summutati keeli sõrmede külgedega. Kuigi isuri-vadja vanad kandled olid samasugused nagu Eestis või Karjalas ning Soomes, hoiti neid mängu ajal süles poolpõiki, lühema servaga ülespidi, nagu seda tegid ja teevad praegugi vene guslimängijad. Küllap see oligi vene mõju, mis isuri rahvapillimuusikas, eriti tantsumuusikas, nagu hilisemas tantsukultuuriski oli üsna tugev. Samas säilitasid isurid väga hästi nii tüüpilise läänemeresoome kandle kuju kui ka erilise kandletegemise laulu, mis oli tuntud ka Eestis. Rahvalaulude uurija Väino Salminen isegi väitis kunagi, et isurid olid kandlesünnilaulu põhilised säilitajad kogu läänemeresoome laulualal. Kandlelaulu eri variantide järgi tehtud imeline kannel kunagi hirvesarvest, või vahtrapuust, samuti ka kalaluudest. Pillikeeled tehti neiu juustest. Kannelt mainitakse muudeski lüürilistes lauludes ja ballaadides. Üheks vadja ja isuri neidude lemmiklauluks oli näiteks laulikneiu jutustus oma helgest ja muretust elust isakodus, kus

isa hoidis tütart kui pilli, veli kandis õde kui kannelt. Pill oli pandud piida peale, kannel kambri ukse peale.

Kunagi kuulsin seda laulu vadja viimaselt suurelt rahvalaulikult Oudekki Figurovalt.

Kannel kui üks mõrvavahend kerkib esile sünges kuid õpetlikus ballaadis Konnolta kosijast. Kandlemees Kalervopoeg Ignatvõi Iivan, kes on muide naisemees, läheb Konno neidude juurde kosja. Need aga ütlevad, et sul ju naine kodus, tapa enne oma naine ja tule uuesti kosja. Ignat kutsub naise saunast välja, võtab kandle ja mängib seni, kuni naine ja lapsed uinuvad. Lõiganud naise pea kui lehed naerilt ja kapsa juurikalt, läheb ta uuesti kosja. Konno neiud vastavad elutargalt: "Tapsid naise, tapad ka meid. Ei keegi meist sulle uueks naiseks tule."

Selle sajandi alguses oli kannel isuri ja vadja külades paiguti üsna populaarne. Luuditsa rannakülas, kus oli 60 talu, mängitud kannelt 7 peres. Kandlemängu hinnati kõrgelt. Sama küla vadjalane Maria Tsarkova, kes ka ise kunagi kannelt mängis, rääkis mulle 27 aastat tagasi, et starika nii üvvi pilliti, shto itkõma pani, garmonia psani pillitä. St. et vanamees mängis nii hästi, et ajas nutma, lõõtspillil sedaviisi mängida ei saa. Tema teadis ka öelda, et kurja väljaajamiseks tuli kannelt mängida. Luuditsa küla teine vadja eideke, Paro Jemeljanova, aga meenutas, et vana vätshi pajati, shto kannel on jumalapilli, a garmoni (st. lõõtspill) on toin. Vaatamata muistse regilaulu säilimisele lauldi ja mängiti-tantsiti selle sajandi alguses tihtilugu juba vene lugusid. 
Isuritele polnud ka eesti lood sugugi tundmatud. Elasid ju nad Eesti naabruses ning nende lähedalgi elas Ingerimaal palju Eesti väljarändajaid. Eesti torupillimeestest vadja pulmades oli juba juttu. On teada, et isurid-vadjalased on selle sajandi algupoolel /mänginud/ ka eesti uuemaid kandleidsimbleid. Juba 1897. a. fikseeris soome folklorist Alava ühe isuri kandlemehe repertuaaris niisuguste lugude nagu Veneläista, Katsanskoita, Ümberkävvä kõrval ka Virolaista. Kahjuks me ei tea, mis lugu see olla võis. Teppo Repo repertuaaris oli muide kolm eesti lugu, ühes on äratuntav ära näiteks meie Savikoja venelane.

Isuri kandlemehe Pavel Mihhailovi leidsin ma 1972. aastal Leningradist ida pool, Neeva jõe kaldal asuvas Kirovi linnas. Käisime tol suvel kolleeg Jelizaveta Richteriga Ingerimaa eesti asundustes. Peatusime mõne päeva ka Leningradis ning siis võtsingi ette reisi selle kandlemehe juurde, kellest kuulsin juba varem tema vennalt Soikkola/Savikülas. Pavel Mihhailov oli tollal 65-aastane. Tema kandlel oli 17 keelt ning pill - või gusli - nagu ta seda meie venekeelses jutuajamises nimetas, oli juba uuemat tüüpi, tehtud 1920. aastail Leningradist toodud malli järgi. Tegelikult oli Pavel Mihhailovi kannel vene kontsertgusli ehk nn. zvontshataja gusli malli järgi tehtud. Vene kontsertgusli väljakujundamises XX saj. algusaastail oli mängus ühe isuri mehe käsi, nii otseses kui ülekantud mõttes. Pavel Mihhailov mängis traditsioonilises katmistehnikas, hoides kannelt serviti põlvedel. Tema repertuaar oli Ingerimaale üsna tüüpiline, näiteks tantsulugu, õigemini venepärane pljaska, mis oli isuritel-vadjalastel üldlevinud tantsuks.

Kui Eestis on valss juba ammu üldtuntud tantsuks, siis Ingerimaale jõudis ta alles käesoleva sajandi algupoolel ja eriti rahvapäraseks ei saanudki, nagu Venemaal muide üleüldse.

Karoobotshka on sajandialguse vene moetants, mis oli populaarne ka meil Setumaal.

Sajandi algupoolel tantsiti külapidudel tihtilugu kannelde saatel, kuigi üldlevinud tantsupilliks oli lõõtspill ehk garmon. Isuri külades on mängitud ka viiulit, balalaikat ning mandoliini ja ka kõiki kokku. Üheks armastatumaks tantsuks oli Ingerimaal kadrill, mis koosnes paljudest duuridest, kuni seitsmeni. Duuride vahele hõigati nende nimetusi, mille järgi tantsijad ümber rivistusid.

Selle sajandi alguses oli Ingerimaa rahvastel kaks linna, kus tööl või kaubareisidel käidi - Narva ja Peterburg. Juba sajandi alguses laulsid vadjalased-isurid toredat laulu, mis algas sõnadega

Shto za gorod,

shto za ljudi,

Narva elab eesti moodi.

Omapäraseks rahvuskultuuride kohtumispaigaks oli ka Peterburi, kus kohtusid kandlemängijaist isurid, vadjalased, soomlased, eestlased, venelased ja lätlased. Olen kandle käekäiku Peterburis ise veidi uurinud ja välja on tulnud üpris huvitavaid seiku. Mis puutub isuritesse, siis sajandivahetusel tuli Peterburi tehasesse tööle kandlemängijast isur Ossip Smolenski, kes mängis 9-keelsel pillil ning asutas oma kandlekoori, kus mängis isegi üks lätlane. Seda kandleorkestrit juhtus kuulma vene rahvapillide suur propageerija ja uurija Nikolai Privalov, kes juba ammu tahtis teha hea vene kontsertguslit Viktor Andrejevi suurvene rahvapilliorkestri jaoks. Koos Ossip Smolenskiga töötas Nikolai Privalov välja vene kontsertgusli kavandi. Kuulus venelasest viiulimeister pidas lihtlabase gusli näidismudeli tegemist enda mainele ohtlikuks ning Nikolai Privalov läks oma kavandiga eestlasest pillimeister Ivan (ilmselt siis Jaan) Normanni juurde, kes elas tollal Peterburis. See tegigi vene kontsertgusli näidismudeli valmis, kuid täiustas seda omakorda eesti uuemalt kandlelt ehk simblilt laenatud detailidega. Uus kontsertgusli, mis oli tegelikult kolme rahva esindaja - isuri, venelase ja eestlase - ühistöö tulemus, läks Venemaal laialt käibele, jõudes lõpuks kaudselt ka isuri 
Pavel Mihhailovi kätte. Järgmine kandlepala on üle Venemaa laialt tuntud pljaskalugu Barinja, ehk siis rahvakeeli Mõisaproua.

Ingerimaa rahvad elavad nüüdki enamasti venepärastes tänav-külades, kus hooned paiknevad tihedalt piki külatänavat. Külatänav on traditsiooniliselt olnud mitmesuguste ühiskondlike ürituste läbiviimise kohaks. Keset tänavat tehti näiteks jaanilõkkeid. Pidupäeval oli tähtsal kohal külanoorte tseremoniaalne jalutamine piki tänavat. Tavaliselt saatis sellist kõndimist neidude laul. See oli nagu setu kulatamine, mis samuti põlvneb vene tavast ja sõnast guljat - 'jalutada'. Tihtilugu saatis kulatamist pillimäng, milleks olid ka erilised, nn. tänava- ehk külalood olemas. Kannel olnud siis kõndival pillimehel nööriga kaelas.

Tahaksin siiski märkida, et kui isuri rahvapillimuusika tundus teile liialt venepärasena, siis vähemalt käesoleval sajandil ta selline juba oli. Ärgem seejuures unustagem, et ida poolt vaadatuna-kuulatuna tunduvad eesti uuemad rahvalaulud ja tantsuviisid üpris saksapärastena, mida nad tegelikult ka on. 